\title{
EXPANDING PLURALISM IN THE AGE OF COVID
}

\author{
Joanne Ginter \\ MA, Registered Psychologist \\ Sundancer Psychological Services, Calgary, Alberta (Canada)
}

\begin{abstract}
Multiculturalism and growing diversity found within client populations encourages therapists to become pluralists in their work. Pluralism is the position, identified by Kenneth Pargament, that therapists take when the cultural story of both the client and therapist are acknowledged to be present in the session. These cultural stories provide the foundation for creative meaning making in the therapeutic process.

The COVID pandemic has set a new bar for therapists in for extending themselves beyond what was once comfortable to being increasingly creative and diversified in meeting their clients' needs. This has involved ways to navigate online or telephone sessions, which subsequently provided therapists with opportunities for interacting with clients outside their typical client base. Or in other words, the need for a broader and more diversified understanding of client needs and ways to promote healing and client resiliency.

This workshop will review the foundational elements of pluralism and the building blocks of resiliency (self, mentor, and community of care) with reference to some of the early literature of the effects of the COVID pandemic on therapists and the therapeutic process. Participants will have an opportunity to identify their position on pluralism and the need for diversity in therapy and the effects of the COVID pandemic on their practice.
\end{abstract}

Keywords: Pluralism, resiliency, cultural self, diversity, COVID.

\section{Introduction}

The increasing multiculturalism found within client populations has been challenging therapists to become more pluralistic in approaching client needs. This client diversity has pressed therapists to frequently practice outside their worldviews. The COVID pandemic which emerged in early 2020 has presented therapists with an additional challenge for meeting client needs as health and safety pushed regulations and intervention strategies beyond previously defined boundaries, including the use of technology to meet with clients through audio or video remote formats and to adapt interventions for delivery outside the therapist's typical therapeutic setting. These changes also posed challenges to ethical codes and standards of practice for regulatory bodies as therapists were being asked to practice in new and challenging ways. In a review of the ethical principles of practice of the APA, Chenneville and Schwartz-Mette (2020) identified the importance of Principle B, "Fidelity and Responsibility" to be particularly relevant in the time of COVID. Under this principle, developing relationships of trust were ones that might require adjustments due to the COVID crisis, including the change to delivery of services, financial limitations, and other unique circumstances such as practicing outside one's typical client population (pp. 644-654).

The need for therapists to adapt in this way aligns with the foundational elements of pluralism found within the therapeutic relationship as identified by Kenneth Pargament. Pargament while researching the relationship between religion and psychology, identified pluralism as preferred modality in addressing multiculturalism in client populations (Zinnbaur and Pargament, 2000). Ginter later identified a modified pluralist position as an expanded position to provide therapists who did not hold a belief in a spiritual ontology to practice as a pluralist (Ginter, 2016). Either position of pluralism offers to therapists the foundation for the inclusion of multiple worldviews to be addressed and acknowledged in the therapeutic relationship.

In the pluralist position, the cultural story of both the client and therapist are acknowledged to be present in the session and provide the foundation for creative meaning making in therapy. This creative meaning making, also known as resiliency, offers to therapists both a language and process for meeting the diversity found within client populations (Ginter, 2016). 


\section{Objectives}

Since the beginning of the COVID pandemic, as therapists have begun meeting with clients outside their regular client base, they have been invited to meet a more diverse set of client needs. In addition, the effects of the COVID pandemic have resulted in included increased anxiety in individuals, increased mental health challenges in children and youth, a broader range of couple problems, and family challenges (Prime, Wade, and Browne, 2020).

Pluralism as a relational process of understanding diverse worldviews offers to therapists a means of addressing these client needs in these new and challenging times. Understanding the building blocks of resiliency, e.g., self, mentor, and community of care, offers a language and process that therapists can use to meet the needs of their clients, in person or remotely, and regardless of cultural identity or community (Ginter, 2016).

\section{Method/discussion}

A general survey of practicing therapists (psychologists, social workers, mental health clinicians) within Alberta, Canada, found that therapists were challenged by video fatigue along with an increase of client and therapist challenges believed to be associated with the effects of the COVID pandemic. Some of these challenges were discussed in a panel discussion at the recent Evolution of Psychotherapy conference in December 2020, when Drs. Stephen Porges, Michael Yapko and Jeffrey Zeig discussed the effects of the COVID pandemic. The overall focus of this panel discussion was 1) to be aware of our own vulnerabilities while questioning who we truly are and what we value; 2) to recognize the need for therapists to find ways to honor their existential goals; and 3) to understand the significant effects of trauma on clients that has been reactivated with the uncertainty of the COVID pandemic. Therapists were encouraged to meet clients where the client is without judgement and with acknowledgement of the client's needs and resources. These challenges in addition to the suggestions provided to therapists were consistent with the position of pluralism where the worldviews, including resources, of the client and therapist are present in therapy (Porges, Yapko and Zeig, 2020).

\section{Conclusions}

In conclusion, therapists are encouraged to expand their practice of pluralism as defined by Pargament and Ginter, whereby both the worldviews of both the client and therapist are accessed to facilitate resiliency in addressing the client's problems. Further the language and process of resiliency can be used to support diverse client populations. A review of current literature indicates that meeting client needs through telepsychology and other remote vehicles is not going away. As well, the psychological effects of the COVID pandemic will likely have an impact on both clients and therapists well into the future (Calkins, 2021).

\section{Workshop Objectives:}

a. Review the foundational elements of pluralism and the building blocks of resiliency (self, mentor, and community of care);

b. Review some of the early literature on the effects of COVID on therapy;

c. Involve participants in interactive activities:

a. Identify their cultural foundations

b. Identify the ways resiliency has been fostered in their lives

c. Share changes participants have made seeing clients during the COVID pandemic

d. Plan for the future

\section{References}

Calkins, H. (2021). Online Therapy Is Here to Stay. Monitor on Psychology, (Jan/Feb), 78-82.

Chenneville, T. and Schwartz-Mette, R. (2020). Ethical issues for Psychologists in Time of COVID-19. American Psychologist, Vol 75, No. 9, 644-654.

Ginter, J. (2016). The Fifth Position: Developing Intercultural Resiliency and Pluralism. Phoenix, AZ: Zeig, Tucker and Theisen. 
Padesky, C. and Siegel, R. (2020) Practical Ways to Improve Telehealth Sessions, National Institute for the Clinical Application of Behavioral Medicine (NICABM). Retrieved May 2020 from Practical Ways to Improve Telehealth Sessions - NICABM

Porges, S., Yapko, M. and Zeig, J. (2020), COVID-19 Impact Panel, Evolution of Psychotherapy, (December 12, 2020). Retrieved Dec 2020.

Prime, H., Wade, M. and Browne, D.T. (2020). Risk and Resilience in Family Well-Being During the COVID-19 Pandemic. American Psychologist, Vol 75, No. 9, 631-643.

Zinnbauer, B. J. and Pargament, K. (2000) Working with the sacred: Four approaches to religious and spiritual issues in counseling. Journal of Counseling and Development, 78 (2), 162-171. Retrieved June 2003) from http://www.psycinfo.com/library/fulltext.cfm 